\title{
DISTRIBUTED COGNITION TRANSFORMATION IN COMPLETE ONLINE SYSTEM ENGINEERING DESIGN TEACHING
}

\author{
Farshad, Sabah; \\ Fortin, Clement
}

Skolkovo Institute of Science and Technology (Skoltech)

\begin{abstract}
Engineering design teams, particularly in academic courses, were no exception to the consequences of the unknown virus and the global pandemic. Forced online teaching has influenced the way of using communication technologies. The information flow architecture of engineering design is also transforming due to the remote activities and the dominancy of web-based technologies. This transformation creates different patterns of distributed cognition within design teams. In the course of full remote teaching, we studied the entire information flow of a small and dispersed engineering team through the early stages of design for one month using the ethnographic method and Distributed Cognition analysis techniques. Our analysis, of the interdisciplinary design team during a rocket engineering project and system engineering teaching, shows the considerable role of different online data sharing and communications technology platforms in distributed cognition and collaborative problem solving within the team. These new trends create new challenges and opportunities, and in order to enhance collaborative design, these emerged out of the box trends require more attention and updating of existing strategies.
\end{abstract}

Keywords: Design cognition, Distributed cognition, Information management, Systems Engineering (SE), Remote teamwork

\section{Contact:}

Farshad, Sabah

Skolkovo Institute of Science and Technology

Center for Entrepreneurship and Innovation

Russian Federation

sabah.farshad@skoltech.ru 


\section{INTRODUCTION}

The COVID 19 crisis has been accompanied by a sharp increase in remote teaching and necessary online design activities. But how has this unpredictable sudden change led to a different approach among engineering students? Should we review the design strategies connected to teaching, collaborating or managing, the design process? In the area of systems engineering and design, even regardless of this new circumstance, normally information at the level of systems and subsystems is distributed across a variety of specialists, and intensive cognitive work is needed to organize and integrate the data into a cohesive design successfully (Greene, Papalambros and McGowan, 2016). Nevertheless, we are facing a major change in the trends of human-computer interaction, which brings even more complexity in the system engineering and design teams' collaboration, communication, and interplay. This is also valid for engineering students learning design in distributed teams.

A recent web article by Iva Marinova (2020) reviews a wide range of trends for remote work in 2020. We have summarized some parts of the report in Table 1. Based on the reported statistics, most of the future work will be in the online mode. In a report published by Gartner (2020), 74\% of companies have a plan to shift parts of their workers to remote work not only during the pandemic but permanently.

Table 1. Remote work trends in 2020

\begin{tabular}{|c|c|c|}
\hline Subject & Statistic & Source \\
\hline Companies that reported an increase in web conferencing time & $67 \%$ & Statista \\
\hline The inclination to continue online working to some extent & $99 \%$ & Buffer \\
\hline $\begin{array}{l}\text { Workers with an option of remote work, who plan to work } \\
\text { remotely more systematically in the next five years }\end{array}$ & $42 \%$ & Owl Labs \\
\hline Forecast of the teams with remote teammates by 2028 & $73 \%$ & Upwork \\
\hline Young managers who support their teams working remotely & $69 \%$ & Upwork \\
\hline $\begin{array}{l}\text { Zoom has been one of the most widely-used applications to } \\
\text { meet the virtual collaboration requirements during COVID-19 }\end{array}$ & $\begin{array}{l}300 \text { million daily } \\
\text { participants reported }\end{array}$ & Zoom \\
\hline The population of remote workers before the pandemic & 4.7 million & Flexjobs \\
\hline $\begin{array}{l}\text { Percentage of worldwide companies that made it mandatory or } \\
\text { supported their workers to work remotely during the pandemic. }\end{array}$ & $88 \%$ & Gartner \\
\hline $\begin{array}{l}\text { Remote employees' opinion about their productivity when } \\
\text { working from home (Accomplishing more in the less or same } \\
\text { time, willing to work longer, and less likely to take time off) }\end{array}$ & $\begin{array}{l}77 \% \text { believe they are } \\
\text { more productive }\end{array}$ & CoSo Cloud \\
\hline $\begin{array}{l}\text { Work-related stress change based on telecommuters } \\
\text { experience }\end{array}$ & $\begin{array}{l}80 \% \text { reported less } \\
\text { stress }\end{array}$ & Amerisleep \\
\hline The distraction rate of people who work from home & $\begin{array}{l}75 \% \text { reported fewer } \\
\text { distractions }\end{array}$ & Flexjobs \\
\hline U.S. telecommuters view as the main benefit of remote work & $\begin{array}{l}53 \% \text { pointed flexible } \\
\text { scheduling }\end{array}$ & Statista \\
\hline $\begin{array}{l}\text { The rise in Google search about "team-building" after the } \\
\text { pandemic }\end{array}$ & $9 \%$ increase & $\begin{array}{r}\text { Think With } \\
\text { Google }\end{array}$ \\
\hline
\end{tabular}

These reports acknowledge the need to rethink the off-site design activities. However, we first should understand the trends of the changes, find effective tools, review emerging procedures and recognize different patterns, and then re-plan accordingly. We had the opportunity to look closer into these challenges for a team of students learning system engineering and practising system development online.

Back at the early 2000s, while explaining a progressive framework for research on Human-Computer Interaction, James Hollan and colleagues (2000) talked about the importance of changing distributed cognition among human and computers because of the new era of technology:

"We are quickly passing through the historical moment when people work in front of a single computer, dominated by a small CRT and focused on tasks involving only local information. Networked computers are becoming ubiquitous and are playing increasingly significant roles in our lives and in the basic infrastructures of science, business, and social interaction" 
Regardless of their notable insight, neither Hollan and colleagues nor anybody else could predict how a virus would speed up the transformation of human interaction with the environment, including human-computer and, human to human relatedness, leading to different cognitive models in activity systems and extending minds.

Distributed Cognition (DC) refers to the principle that assumes cognitive processes are not limited to people's internal thought processes but include external representations such as the information systems, designs, and interacting technologies they work with (Brereton, 2004). Some scholars have recently featured studying system/design engineering from a cognitive science perspective and used DC techniques (Greene, Papalambros and McGowan, 2016). Based on research evidence, they believe that, especially in the early phases of the project where conceptual design occurs, non-engineering factors, like cognitive processes, are expected to be most influential over system design. Former studies have also analyzed the information flow in engineering teams with the DC approach (Sharp, Giuffrida and Melnik, 2012). We have used the same structure and approach in this paper, with the difference that our emphasis has been on studying the design procedure within a multidisciplinary team during a systems engineering teaching project while the entire design flow has moved remotely. This study has observed cognitive processes and changes of information flow architecture through a DC perspective. In the next sections, respectively, the concept of DC and its application for investigating teamwork is briefly introduced, then the study, the team, and data gathering explained. The analysis method section is presented in the 4th part, including; physical layout of the team members, artefacts and information flow. In the 4th section, we also showed how simple communication platforms such as Telegram, Google docs, and Zoom, play a more prominent role than sophisticated collaboration platforms such as Git and MagicDraw in the design process. Our findings are discussed in section 5, and the conclusion appeared in section 6 including future directions for research.

It is worth underlining that this case is our first step in studying web-based collaborative design and engineering problem solving in a $\mathrm{PhD}$ thesis. As discussed in the conclusion and future work, one of the significant goals behind this study is to shed more light on future steps and vision for the project.

\section{DISTRIBUTED COGNITION}

Despite the traditional view in the cognitive sciences that the individual's brain plays an exclusive role in the cognition process, Distributed Cognition Theory (DCT) developed a different and more modern perspective in which forms of the extended mind pop up, such as complex sets of connections between individuals and artefacts in a certain task (Hutchins, 1995). Hollan et al. (2000) believe that to design efficient human-computer interactions and to understand human cognitive functions, we must grasp the nature of these distributions of processes. In DCT, we expect to find a system that can run a dynamic self-configuration to coordinate subsystems to accomplish different functions. In fact, rather than through the elements' spatial colocation, a cognitive process is bounded by the functional links among the elements that engage in it. Based on the DCT principles to observe human activities, at least three kinds of cognitive process distribution are perceptible:

- $\quad$ Distributed cognitive processes across the members of a social group;

- Involved cognitive processes in coordination between both internal and external structures;

- Distributed processes through time in which the products of initial events can transform the nature of following events.

According to this view, in addition to the larger field of cognition processing, and the important role of communication between different elements in a system, one can note a particular focus on the way of transforming and propagating information within the system to deliver collaboration.

Different studies on teams of software development, co-located agile engineering, and transportation, have applied this approach to analyse the team performance and information flows (Sharp et al., 2006; Dreyfus, 2007; Sharp, Giuffrida and Melnik, 2012; Andreasson, Jansson and Lindblom, 2019). Although a wide range of papers has used this approach to study a combination of remote and on-site engineering projects, the current situation of full-remote-work is new, and we could not find a study on completely online teaching/teamwork based on the same method.

The analysis in this paper relied on DCT to explore how information flows in all directions during remote teamwork of a system engineering teaching and related design operations. We might have a chance to compare the results later with an on-site teaching and work procedure after the current 
lockdown. Along with previous explanations of Distributed Cognition, we used the DiCOT technique to analyse the information flows of the team. In the next section, we briefly describe this method and then discussed it in detail in section 4 .

\subsection{Distributed Cognition for Teamwork (DiCOT)}

Blandford and Furniss (2005) developed DiCoT as a method and representational system to support the analysis of Distributed Cognition within small working teams.

The DiCoT technique includes three basic themes:

- The first theme is related to the physical environment of the cognitive system.

- The second theme focuses on the artefact's details.

- The third theme pays attention to information flow and the way that information flows within the cognitive system, the media or tools, which facilitate the transforming information process.

A set of principles obtained from Distributed Cognition are defined in DiCoT to map the three themes for a deeper investigation. In section 4, we explain these themes, their principles, and related analysis.

\section{THE STUDY}

A team of students designing and developing a rocket for a rocket engineering competition (IREC, 2020) was studied. While learning the various stages of System Engineering (SE), the team must design, build, and launch a rocket carrying a payload of no less than $4 \mathrm{~kg}$ to a target apogee of $3 \mathrm{Km}$ above ground level and land the rocket parts on the ground without any damage. The mission supported by Skoltech Space Centre and, participants were $\mathrm{PhD}$ and Master programs students from the SE course. The first phase of the system engineering development and design before the Preliminary Design Review (PDR), and Critical Design Review (CDR) observed in this study ran for one month during November 2020, and included; Mission Objectives, Concept of Operations, Mission Requirements, System Requirements, System Architecture, Product Breakdown Structure (PBS), Work Breakdown Structure (WBS), Stakeholder Analysis, Risk Analysis, and Preliminary Design.

\subsection{The Team}

The team involved in the project consists of three different groups: the main group, seven engineers from different disciplines; the second group, two mentors from the Space Centre Engineering at Skoltech. One of the mentors was the course instructor and the second mentor a member of the group as a technical advisor. The third group was composed of a network of external advisors with significant experience in this type of project. All groups were dispersed worldwide and had only online contact during the various stages of project development throughout the whole study. The team was a good example of absolute remote engineering design. An outline of the roles and countries of the main team members (the main team was the central focus of the study) is specified in Table 2. None of the members were native English-speakers, but the main language of the project, all documentation and communications were in English.

Table 2. The main team roles and countries

\begin{tabular}{|l|l|l|l|l|c|c|c|}
\hline ID & $\begin{array}{l}\text { Expertise/ } \\
\text { Degree/Gender/Age }\end{array}$ & Role & Country & ID & $\begin{array}{c}\text { Expertise/ } \\
\text { Degree/G/Age }\end{array}$ & Role & Country \\
\hline M1 & $\begin{array}{l}\text { Space Engineering/ } \\
\text { MSc/Female/22 }\end{array}$ & Coord. & Russia & M5 & $\begin{array}{c}\text { Space Engineer/ } \\
\text { PhD/M/32 }\end{array}$ & Mentor & Russia \\
\hline M2 & $\begin{array}{l}\text { Engineering Systems/ } \\
\text { PhD/Male (M)/41 }\end{array}$ & $\begin{array}{l}\text { System } \\
\text { Engineer }\end{array}$ & Iran & M6 & $\begin{array}{c}\text { Mechanical } \\
\text { Engineering/M/ } \\
26\end{array}$ & $\begin{array}{c}\text { Mechanical } \\
\text { Design }\end{array}$ & Pakistan \\
M3 & $\begin{array}{l}\text { Robotic/ } \\
\text { MSc/M/23 }\end{array}$ & $\begin{array}{l}\text { Mech. } \\
\text { Eng. }\end{array}$ & Russia & M7 & $\begin{array}{c}\text { Electronic } \\
\text { Engineering/ } \\
\text { MSc/M/24 }\end{array}$ & $\begin{array}{c}\text { Electronics } \\
\text { Design }\end{array}$ & Russia \\
\hline M4 & $\begin{array}{l}\text { Aerospace/ } \\
\text { MSc/M/24 }\end{array}$ & $\begin{array}{l}\text { Modeling } \\
\text { - 3D }\end{array}$ & Egypt & & & \\
\hline
\end{tabular}

\subsection{Data Gathering}

We used the anthropology informed approach to gather data for our study (Bentley et al., 1992). One of the researchers is a member of the team under the study who participated as a system engineer. It is 
also an accepted method in virtual ethnography (Hine, 2000) and helped the researcher to have a better understanding of team members' viewpoints during virtual meetings.

The researcher is a member of the team virtual group and directly observed the members activities in text-based connections, during 62 hours of 27 video sessions, the design iterations, and preparation for PDR and CDR. We recorded all the sessions via 49 hours of video recording and six hours of voice recording. The researcher also had access to the pairing section recordings and text messages by uploading the backup of conversation to a virtual archive channel by the involved members who accepted to be observed throughout the study. The collected data included recordings, screenshots, observation notes, online documentation activities and text messages. Moreover, a brief questionnaire (Table 3) was answered by each team member about the details of the way and time in which they shared information.

Table 3. Questions about sharing information adopted and modified from Sharp et al. (2012)

1. How do you share the project information with your teammates?

2. How often do you reach out your teammates, and how, e.g. WhatsApp call with M1 every day $\mathrm{x}$ times for $\mathrm{x}$ minutes?

3. Are there any information or files that you think do not need to share? Please outline examples with indicating why you believe so.

4. If you come across a situation you think you could act better in a face-to-face meeting. Please example and reasons. What you have done in such situations?

\section{DICOT ANALYSIS}

\subsection{Physical Layout of the team members}

The physical layout of all the team members' workspace was their home offices and varied in terms of the form of the space they used and how the working environment might help their work activities. The DiCoT framework of Physical layout parameters is summarized in Table 4.

Table 4. Physical layout adopted from Sharp et al. with permission (2012; 2016)

\begin{tabular}{|l|l|}
\hline Space and cognition & The use of space to support activity, e.g. laying out materials \\
\hline Perceptual & How spatial representations aid computation \\
\hline Naturalness & $\begin{array}{l}\text { How closely the properties of the representation reflect those of } \\
\text { what it represents }\end{array}$ \\
\hline Subtle bodily supports & Any bodily actions used to support activity, e.g. pointing \\
\hline Situation awareness & $\begin{array}{l}\text { How people are kept informed of what is going on, e.g. through } \\
\text { what they Can see, what they can hear and what is accessible to } \\
\text { them. }\end{array}$ \\
\hline Horizon of observation & $\begin{array}{l}\text { what an individual can see or hear (this influences situation } \\
\text { awareness) }\end{array}$ \\
\hline $\begin{array}{l}\text { Arrangement of } \\
\text { equipment }\end{array}$ & $\begin{array}{l}\text { How the physical arrangement of the environment affects access to } \\
\text { Information. }\end{array}$ \\
\hline
\end{tabular}

\subsubsection{Space and Cognition}

Based on interviews with members, physical space was limited to the workers' desk during this project. Scattered notes in a notebook or scraps of paper were used temporarily and were not properly archived for later use. Schedules and important events were set up virtually.

One of the most used methods to ensure everybody had quick access and was made aware of new changes was pining a specific post in the virtual Telegram group. This approach corresponds to a physical bulletin board, where important announcements are pinned.

\subsubsection{Perceptual and Naturalness}

Relying deeply on working in the virtual setting has narrowed spatial perception that are affected by signals received from these information resources. In general, each person received information from three different monitors. Usually a laptop, a monitor in Extend Project mode, which connected to a laptop, and a personal smartphone (see Figure 1). For some members, more monitors were used. It is 
not easy to measure the naturalness principle of the physical layout, and difficult to evaluate how the presentation of data for members was natural, because most of the members were in their first experience for this type of project and environment.

\subsubsection{Subtle bodily supports}

Since all team-related activities took place in the virtual environment, there was no expressive physical gesture or movement that could be reported as a principle regarding subtle bodily supports. It is almost impossible to read the body language correctly in virtual space because there is no natural gesture in text-based conversations, and during video meetings, you can only see a face or mostly people tend to turn off their videos. Though tagging people in-group chat spaces or using emoji cartoons was very common, inferencing this kind of virtual gestures is not reliable as subtle bodily support for at least two reasons; first, they are quite limited and predesigned features, and second, we could not find solid evidence that has studied this area.

\subsubsection{Situation awareness}

The team members relied on Telegram group chat for meeting invitations, event reminders, link to documents, sharing resources and mandates, etc. Announcement on the Telegram instant messaging group is the primary mean of being aware of all project milestones and activities. The coordinator updates the situation after any change and posts it in the chat group to ensure everyone is aware of the situation. In necessary situations, tagging (using @+ID creates a signal notification for the person) is used to confirm the corresponding person has seen the post. According to observations, although the concurrent use of several artefacts and the instantaneity of announcements increases the cognitive load, which is a big challenge and needs investigation, situation awareness generally happens effectively.

\subsubsection{Horizon of observation and arrangement of equipment}

The members' horizons concerning this project and teamwork were clearly limited to the monitors in front of them. Given that $100 \%$ of activities under this study were performed remotely, and it was a temporary short mission, it was not possible to provide a specific physical horizon of observation. Figure 1 shows a typical horizon of observation and arrangement of equipment.

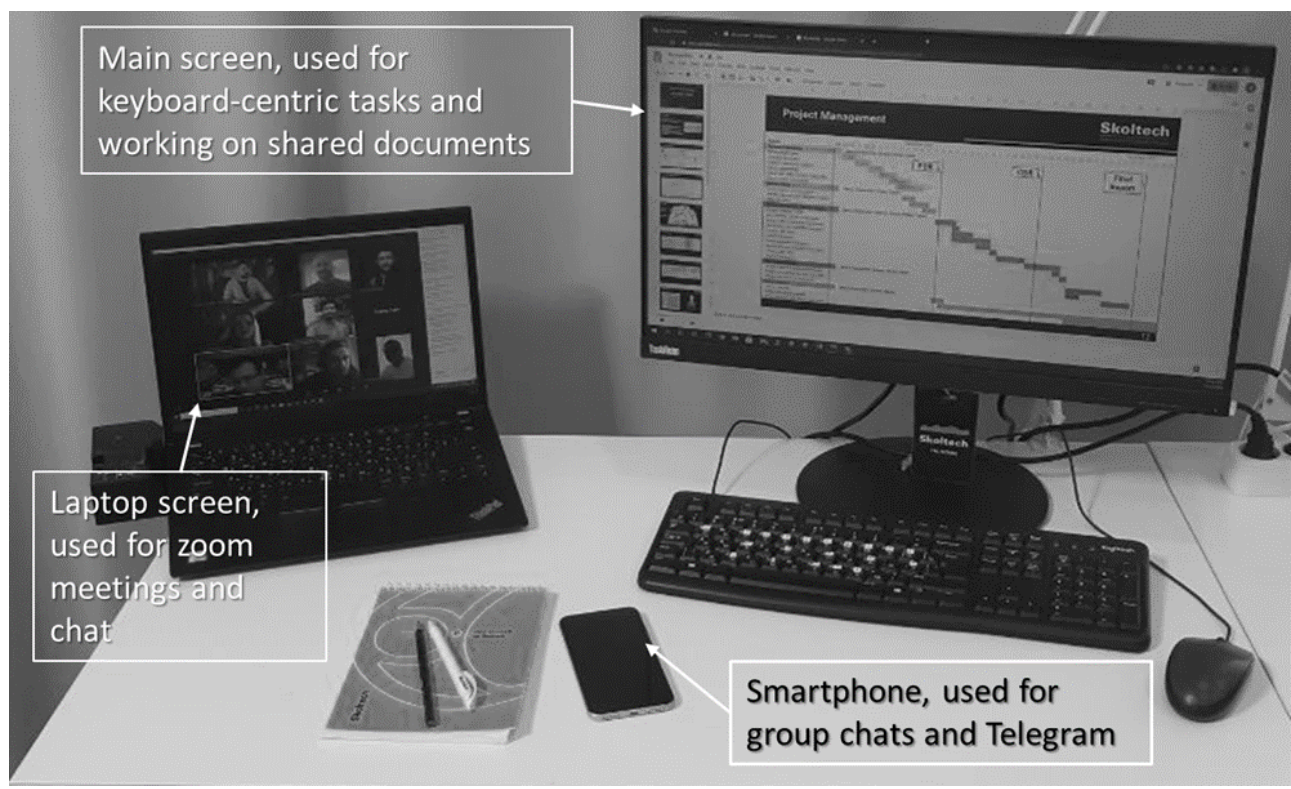

Figure 1. A sample of the horizon of observation of team members during remote work

\subsection{Artefacts and Information Flow}

The next two themes for analysis concentrates on the role of artefacts and information flow more precisely. The analysis focuses on the communication among the team members, their roles and the patterns of events, which define the system's mechanics (Blandford and Furniss, 2005). Table 5 presents the main virtual artefacts that played essential roles in the team collaboration in this project. 
In the table, the Usage Rating column represents the team members' opinion about the level of usage of any artefact based on time and volume of information transfer (most used A and the least used E).

Table 5. The main virtual artefacts

\begin{tabular}{|l|l|l|l|}
\hline Application/Platform & Capabilities & What the team handled with it & $\begin{array}{l}\text { Usage } \\
\text { Rating }\end{array}$ \\
\hline $\begin{array}{l}\text { Telegram } \\
\text { (Durov Nikolai, 2013) }\end{array}$ & $\begin{array}{l}\text { a cross-platform based on } \\
\text { cloud, ability to instant } \\
\text { messaging, group } \\
\text { communication, calling, and } \\
\text { Voice over Internet Protocol }\end{array}$ & $\begin{array}{l}\text { Communicate with teammates, } \\
\text { share information and exchange } \\
\text { links. Also, conducting polls for } \\
\text { appointments. }\end{array}$ & A \\
\hline $\begin{array}{l}\text { Google Docs (Google, } \\
\text { 2020) }\end{array}$ & $\begin{array}{l}\text { Free online documents for } \\
\text { instant documents sharing and } \\
\text { co-working }\end{array}$ & $\begin{array}{l}\text { Sharing information, working } \\
\text { simultaneously on documents. } \\
\text { Usually accompanied with Zoom }\end{array}$ & B \\
\hline $\begin{array}{l}\text { Zoom } \\
\text { (Zoom Video } \\
\begin{array}{l}\text { Communications Inc, }, \\
\text { 2020) }\end{array}\end{array}$ & $\begin{array}{l}\text { Online video services, by peer- } \\
\text { to-peer cloud-based platform } \\
\text { and provides teleconferencing, } \\
\text { telecommuting. }\end{array}$ & $\begin{array}{l}\text { Team meetings, negotiation } \\
\text { sessions, networking with } \\
\text { consultants and mentors, and in- } \\
\text { team coordination }\end{array}$ & C \\
\hline $\begin{array}{l}\text { Miro } \\
\text { (Khusid Andrey, } \\
\text { 2020) }\end{array}$ & $\begin{array}{l}\text { An online platform for visual } \\
\text { collaboration and teamwork. } \\
\text { Provides a whiteboard. }\end{array}$ & $\begin{array}{l}\text { This virtual whiteboard provides a } \\
\text { place to a simultaneous drawing } \\
\text { of charts and forms }\end{array}$ & D \\
\hline $\begin{array}{l}\text { MagicDraw } \\
\text { (No Magic, 1995) }\end{array}$ & $\begin{array}{l}\text { A visual modelling tool for } \\
\text { team collaboration. And the } \\
\text { ability of analysis and design } \\
\text { of engineering systems. }\end{array}$ & $\begin{array}{l}\text { A limited volume of modelling } \\
\text { activities performed in this } \\
\text { environment. }\end{array}$ & E \\
\hline $\begin{array}{l}\text { Git } \\
\text { (Git, 2020) }\end{array}$ & $\begin{array}{l}\text { A system for distributed } \\
\text { version control and tracking } \\
\text { changes in documents. }\end{array}$ & $\begin{array}{l}\text { Control the versions and tracking } \\
\text { any changes. }\end{array}$ & E \\
\hline
\end{tabular}

Based on the DiCoT methodology, the second theme is considering the way that artefacts are designed to support cognition from the perspective of DC. From this perspective, the environment that the team (or team members) inhabit has a pivotal role in cognition, including: all artefacts, tools, representations, and environmental resources (Blandford and Furniss, 2005). Table 6 shows the DiCoT framework for information flow.

Table 6. Information flow framework, adopted from Sharp et al. (2012; 2016)

\begin{tabular}{|l|l|}
\hline Information movement & The mechanisms used to move information around the cognitive system \\
\hline Information transformation & $\begin{array}{l}\text { When, how and why information is transformed as it flows through } \\
\text { the cognitive system }\end{array}$ \\
\hline Information hubs & Central focuses where information flows meet and decisions are made. \\
\hline Buffers & $\begin{array}{l}\text { Where information is held until it can be processed without causing } \\
\text { disruption to ongoing activity. }\end{array}$ \\
\hline Communication bandwidth & The richness of a communication channel \\
\hline Behavioural trigger factors & Cause activity to happen without an overall plan \\
\hline
\end{tabular}

Also, Figure 2 represents how information flow happened within the dispersed team. Communication among all team members occurred completely through virtual interactions and mostly in group chats. Models in Figure 2 illustrate two different phenomena in artefacts utilities and information flow procedures; in model A, you see a collection of applications/platforms inside a circle used by the team members during collaboration, communication, and information sharing. All team members connected to the circle over a two-way line, which means they send and receive all that data through this model. The line of the team coordinator is thicker, which shows a higher volume of connections. Inside the circle, Telegram gained the largest share of usage, and MagicDraw is the smallest one with fewer usages. According to our data, if we divide artefacts into two distinct categories, communication versus technical, there is no significant difference in the summation time spent in each category 
(Telegram + Zoom Vs Google doc + Miro + Git + MagicDraw). Model B illustrates the team's pairing network; as shown in the drawing, most of the members had a connection with each other. While some members show more paring connections (thicker dashed lines), fewer or no connection cases were observed. The coordinator, for instance, had the maximum number of connections and collaborative activities. We also did not detect any relationship between members' backgrounds and their network strength, while members working in the same section made more connections together.

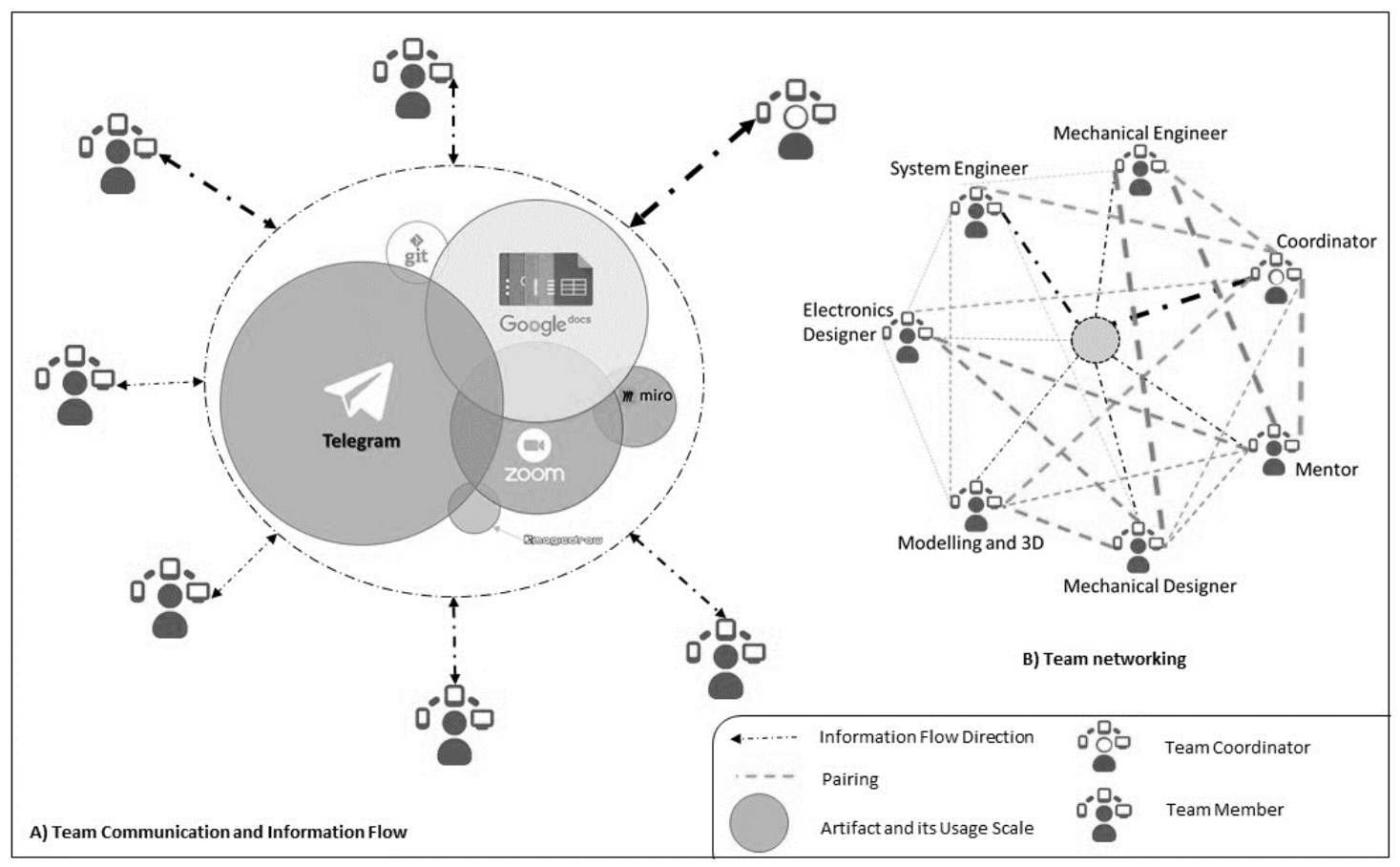

Figure 2. A) Team communication and sharing information layout all over artefacts, the size of the circle shows the scale of usage. B) Pairing network, the thickness of lines indicates the strength of the connection.

\section{DISCUSSION}

The forced ubiquitous remote teaching and teamwork following the pandemic challenges, made us study team collaboration, distributed cognition, information flow, and used artefacts during an engineering design teaching project from a different perspective. We used DC and DiCoT techniques for modelling similar studies. We have reported a case with particular features: First, the whole project was conducted online without any face-to-face meetings; Second, the team was dispersed in different countries and had never met before; Third, the team consisted of interdisciplinary specialities, and the essence of the project is interdisciplinary as well. The study's findings are in conformance with the results of similar studies on agile software development teams (Sharp, Giuffrida and Melnik, 2012; Deshpande et al., 2016) where remote complex collaboration can be successful. We can also add that web-based complex engineering design teaching can be successful despite the observed limitations. In the studied dispersed team, communication and collaboration were feasible, largely through Telegram chats and Zoom meetings, while documentation, sharing of information, and co-working mostly happened via Google docs and Telegram. Based on our observation, communication was mainly in text messages, with an informal style, and members were easily available for any unarranged conversations over Telegram. Formal communication forms, using email, telephone or mobile calls, and using short message services (SMS) were not observed. This is not in line with traditional engineering collaboration. The communication process was not limited to the group. Regardless of the geographical interval, we received reports that some members collaborated on a day-to-day basis with colleagues in pairs via text messages, screen sharing, video, and audio online calls.

Distributed Cognition analysis in previous studies, such as an observation on a co-located agile team (Sharp et al., 2006), outlined three main considerations: First, existing mediating artefacts are few in the system and simple; Second, fluent and open information flow occurs, thus enhancing situational 
awareness; Third, the team operates in an information-rich environment where applicable information is simply available and instantly relevant. Our observations are well in line with the second and third considerations, at the same time, we observed the usage of several mediating artefacts both simple and easy to use (Telegram, Zoom, Google Docs, Miro) or detailed and sophisticated (Git, Magicdraw), though usage of simple artefacts was higher. This observation is certainly due to the early conceptual design phase covered in the project.

We would also like to point out some limitations of the study. This paper reported only a single case study of a small, dispersed engineering team, whereas the main theme was teaching. We tried to cover the majority of the development work. Still, we cannot ignore that the observation period was short. We do not know if in the long work procedures, the team member will still keep their motivation and passion for collaboration in a remote mode or not, or how the patterns of artefacts usage would change. Only one location was visited, and no more on-site observation was possible. The noted limitation, however, is mitigated since one of the authors was a member of the team.

Moreover, we believe that the DiCOT methodology designed for observing a physical environment, does not completely engage with the full virtual setting and needs to be upgraded. It causes some limitations in observation processes. For instance, the Physical Layout items are intrinsically designed for co-located situations, not a virtual environment. In more details, we think that: Space and cognition (The use of space to support activity, e.g. laying out materials) is better to deal with the virtual environment of the application/platform; Perceptual (How spatial representations aid computation) can inquire about in-app features, Naturalness (How closely the properties of the representation reflect those of what it represents) will be more useful if modified with virtual teamwork, Subtle bodily (Any bodily actions used to support activity, e.g. pointing) will be more adequate if consider commenting ways or use of emojis. We tried to alleviate this weakness by equating cyberspace with observing some physical elements, such as the virtual announcements, instead of a physical board on the wall.

\section{CONCLUSIONS AND FUTURE WORK}

We used Distributed Cognitive (DC) theory to observe changes happening in the cognitive processes and information flow in a different environment and complex collaborative engineering design teaching while everybody was isolated at home due to a worldwide pandemic. We collected our data by actively participating in the events, close observation, recordings and using questioners. And then, we mapped how collaboration, communication and sharing information accrue in these situations.

The DC analysis in our study on a remote design project within a dispersed engineering team shows some important notes. First, teaching system engineering and complex design procedures to postgraduate students is feasible through complete off-site programs and computer-based online communication and collaboration platforms with an acceptable learning level. As the PDR and CDR results showed, the team under the study recorded a score of A based on the course instructors evaluation and follow-up observation in the final report and examination. Second, the information flow architecture within the team is more complex than that in the same ordinary or co-located teams in different directions. Our engineering team relied on some digital complex artefacts with sophisticated structures at the same time, used simply designed artefacts but in a complex way. Third, Sharing information required to be explicitly performed, and all information needed to be available and transformed almost immediately. Fourth, the way information was shared, including what, when and how, is an individual decision made by the team members. These points are relevant for defining strategies for remote work. Fifth, we did not observe any usage of previously common models of communication such as email, telephone calls or SMS, this shows a significant change in the information flow architecture. Because of this change, however, some features of team studies are more feasible, as we can more easily access most of the activities' history and record events to further analysis. Sixth, while different complex social networks were created within the team, they are mostly trackable and well documented because using platforms, especially text-based and voice messages, are easily available for later reference. This point indicates a distributed computer-based memory as a part of team cognition.

Moreover, we did not receive any report about communication problems; however, some misunderstandings happened during text messages, and tension rose between two team members. We do not know if this challenge can become more serious and common in the long run. This may be the case of future investigations along with observing the possible change of using artefacts during further 
development phases. Other future studies can include teams' work in more advanced stages of the design or compare the same missions in a different context-for example, DC Analysis in hybrid or entirely co-located system engineering teams. Furthermore, we did not investigate the matter of information security in this study which could be a subject for future work, especially in the context of remote engineering design and its connection with Distributed Cognition. This sort of analysis could be applied to investigate the role of artefacts and the architecture of information flow to understand distributed cognition among engineering design teams out of academia. In addition, examining the team network through Social Network Analysis, indexes such as density, centrality, betweenness, etc., among team members would probably enhance our understating. Further, we believe that the matter of managing cognitive load in remote engineering teaching is a serious case to be investigated.

We are also planning to study collaboration by measuring the differences in members' engagement in activities (this is highly possible because of the access to history logs) and examining the impact of providing feedback to improve it.

\section{ACKNOWLEDGMENTS}

The authors would like to thank Professor Anton B. Ivanov and RocketSKY team at Skoltech Space Centre that openly allowed the research team to access all information and record the events.

\section{REFERENCES}

Andreasson, R., Jansson, A. A. and Lindblom, J. (2019) "The coordination between train traffic controllers and train drivers: a distributed cognition perspective on railway," Cognition, Technology \& Work. Springer, 21(3), pp. 417-443.

Arlington, V. (2020) Gartner HR Survey, Gartner. Available at: https://www.gartner.com/en/newsroom/pressreleases/2020-03-19-gartner-hr-survey-reveals-88--of-organizations-have-e.

Bentley, R. et al. (1992) "Ethnographically-informed systems design for air traffic control," in Proceedings of the 1992 ACM conference on Computer-supported cooperative work, pp. 123-129.

Blandford, A. and Furniss, D. (2005) "DiCoT: a methodology for applying distributed cognition to the design of teamworking systems," in International workshop on design, specification, and verification of interactive systems. Springer, pp. 26-38.

Brereton, M. (2004) "Distributed cognition in engineering design: Negotiating between abstract and material representations," in Design representation. Springer, pp. 83-103.

Deshpande, A. et al. (2016) "Remote working and collaboration in agile teams."

Dreyfus, D. (2007) "Information system architecture: Toward a distributed cognition perspective,” ICIS 2007 Proceedings, p. 131.

Durov Nikolai, D. P. (2013) “Telegram.” Dubai. Available at: https://telegram.org/.

Git (2020) Git. Available at: https://git-scm.com/.

Google (2020) Google Docs. Available at: https://www.google.com/docs/.

Greene, M., Papalambros, P. Y. and McGowan, A.-M. (2016) "Position paper: Designing complex systems to support interdisciplinary cognitive work," in DS 84: Proceedings of the DESIGN 2016 14th International Design Conference, pp. 1487-1494.

Hine, C. (2000) Virtual ethnography. Sage.

Hollan, J., Hutchins, E. and Kirsh, D. (2000) "Distributed cognition: toward a new foundation for humancomputer interaction research," ACM Transactions on Computer-Human Interaction (TOCHI). ACM New York, NY, USA, 7(2), pp. 174-196.

Hutchins, E. (1995) Cognition in the Wild. MIT press.

IREC (2020) The Intercollegiate Rocket Engineering Competition, ESRA Spaceport America Cup page. Available at: http://www.soundingrocket.org/what-is-irec.html.

Khusid Andrey (2020) Miro. Available at: https://miro.com/about/.

Marinova, I. (2020) 28 Need-To-Know Remote Work Statistics Of 2020, Review 42. Available at: https://review42.com/remote-work-statistics/.

No Magic (1995) "MagicDraw.” Available at: https://www.nomagic.com/products/magicdraw.

Sharp, H. et al. (2006) "The Role of Story Cards and the Wall in XP teams: a distributed cognition perspective," in AGILE 2006 (AGILE'06). IEEE, pp. 11-pp.

Sharp, H., Giuffrida, R. and Melnik, G. (2012) "Information flow within a dispersed agile team: a distributed cognition perspective," in International Conference on Agile Software Development. Springer, pp. 62-76.

Zoom Video Communications Inc (2020) “Zoom." San Jose, California. Available at: https://zoom.us/. 